Furthermore high vascular lesions may present high perfusion as well as brain cancer.

The symmetrical calcifications and the diffuse enhancing nodular lesions are other important findings that suggest a diffuse cerebral condition. Actually the nodular enhancing lesions constitute pre-cystic lesions as same cases show in the literature. Actually the leucodistrophy described in this entity is rather related to vasogenic edema and gliosis surrounding the cysts and the nodules ${ }^{1-5}$.

LCC is a very rare disease and less than 30 cases reported since the original description by Labrune and colleagues, all of them with characteristically infantile or juvenile onset ${ }^{1-3}$. Sener et al. were the first to suggest the existence of an adult form of this disease, based on the observation of a slow clinical progression in a patient with onset in late adolescence ${ }^{4}$. Wargon et al. report a 30-year-old woman with a lacunar infarct as the first manifestation of $\mathrm{LCC}^{5}$. In our patient, the diagnosis of LCC was based on the highly suggestive neuroradiological findings which were almost identical to previous report . Our biopsy showed no neoplastic cells, but clotted blood within the lesion.

LCC is an entity can present with cystic expansive lesions with mass effect, hemorrhagic content and high vascular density that can be misunderstood as neoplastic lesions. Symmetrical brain calcifications and dif- fuse enhancing hemorrhagic nodules are the other crucial findings. These abnormalities points out that this enity should rather be descrided as a vascular entity in the books than as a primary leucodistrophy.

\section{REFERENCES}

1. Labrune P, Lacroix C, Goutieres F, et al. Extensive brain calcifications, leukodystrophy, and formation of parenchymal cysts: a new progressive disorder due to diffuse cerebral microangiopathy. Neurology 1996;46: 1297-1301.

2. Kaffengerger T, Valko PO, von Meyenburg J, et al. A case of late onset leukoencephalopathy with cerebral calcifications and cysts in 59-year-old woman. Eur J Neurol 2009;16:278-281.

3. Marelli C, Savoriardo M, Fini N, et al. Late presentation of leucoencephalopathy with calcification and cysts: report of two cases. J Neurol Neurosurg Physchiatry 2008;79:1303-1304.

4. Sener U, Zorlu Y, Men S, Bayol U, Zanapalioglu U .Leukoencephalopathy, cerebral calcifications and cysts. Amer J Neuroradiol 2006;27:200-203.

5. Wargon I, Lacour MC, Adams D, Denier C. A small deep infarct revealing leukencephalopathy, calcifications and cysts in an adult patient. J Neurol Neurosurg Psychiatry 2008;79:224-225.

LEUCOENFALOPATIA, CALCIFICAÇÕES CEREBRAIS E CISTOS: ENTIDADE QUE PODE SIMULAR UMA NEOPLASIA

${ }^{1}$ Serviço de Neurocirurgia, Hospital Governador Celso Ramos, Florianópolis SC, Brazil; ${ }^{2}$ Serviço de Radiologia, Clínica Imagem, Florianópolis SC, Brazil.

Conflicts of interest: The authors report no conflict of interest

Correspondence: Melina Moré Bertotti - Rua Coronel Américo 1679 - 88117 311 São José SC - Brasil. E-mail: melinamore@hotmail.com

Received 12 March 2011. Accepted 30 March 2011.

\title{
Pial arteriovenous fistula in the posterior fossa
}

\author{
Luciana Rossi Guerra', Leandro de Assis Barbosa², Livia Guidoni de Assis Barbosa², \\ Derval de Paula Pimentel ${ }^{4}$, Fabrízio Isaac Schawb Leite $^{5}$
}

Intracranial pial arteriovenous fistulas (AVFs) are rare congenital abnormality that can cause severe morbidity and mortality, particularly in neonates ${ }^{1}$. AVFs are rare cerebrovascular lesions of the brain that were considered to be distinct from other arteriovenous malformations (AVMs) by Lasjaunias, in $1986^{2}$. Intracranial pial AVFs have a single or multiple arterial connections to a single venous channel. They differ from brain AVMs in that they lack a true nidus. They differ from dural AVFs in that they derive their arterial supply from pial or cortical arteries and are not located within the dura mater ${ }^{3}$. They may be localized anywhere in the brain but display a preference for the supratentorial regions ${ }^{3}$.
Pial AVFs can be acquired traumatically or iatrogenically or may be congenital. Their natural evolution is unfavorable, conservative management of pial AVFs has been associated with mortality in $63 \%$ of patients ${ }^{4}$.

\section{CASE}

A 6-month old boy present macrocephaly, asymptomatic, without apparent motor injury, did not show any skin lesion and no signs of heart failure. A transfontanele ultrasound Doppler showed evidence of large arteriovenous shunt (AVS) at posterior fossa with patent flow (Fig 1A and 1B). Additional investigation with computed tomography (Fig 1C) and magnetic resonance 


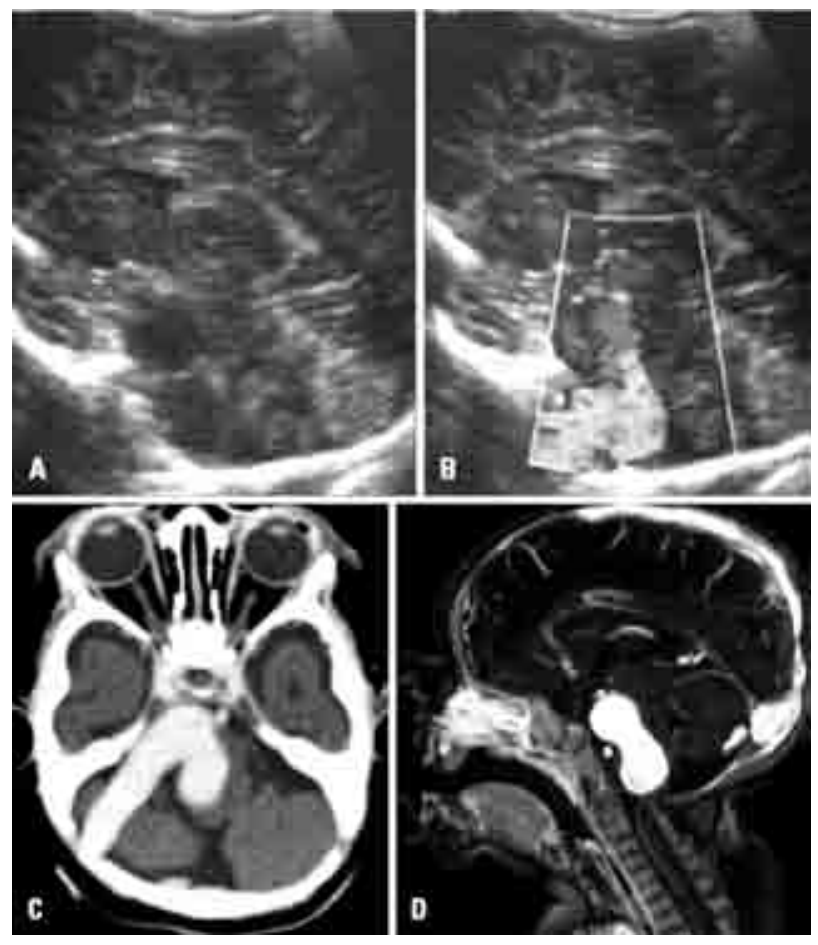

Fig 1. [A and B] Color Doppler transfontanele ultrasound showing a tubular image with patent flow in posterior fossa. [C] CT scan demonstrated large vascular structure occupying part of posterior fossa. [D] MRI T1 weighted in sagittal views, demonstrated the extent of the injury and the compressive effect on the brain stem.

showed extensive vascular mass partially occupying posterior fossa, leading to displacement and compression of the brainstem and no signs of hydrocephalus. The magnetic resonance (Fig 1D) and digital subtraction arteriography (Fig 2A and 2B) confirmed AVF with single feeder originated from the vertebrobasilar junction and single draining in cerebellar vein toward torcule.

The AVF was treated via an endovascular route with detachable coils. Elective embolizations of the AVFs were done with coils at 6 months of age, resulting in complete exclusion of the lesions, as shown on the postembolization internal carotid angiogram on anterior posterior and lateral views (Fig 2C and 2D).

\section{DISCUSSION}

Intracranial pial AVFs are rare cerebrovascular lesions. They are a direct communication between a pial artery and cerebellar vein, without an intervening nidus and located in the subpial meningeal space. This newly distinguished subtype of intradural AVS is necessary because it corresponds to an architecture that engenders specific symptoms, occurs in a special age group, constitutes the phenotype of a well-defined disease, and requires a specific therapeutic technical approach ${ }^{5}$.

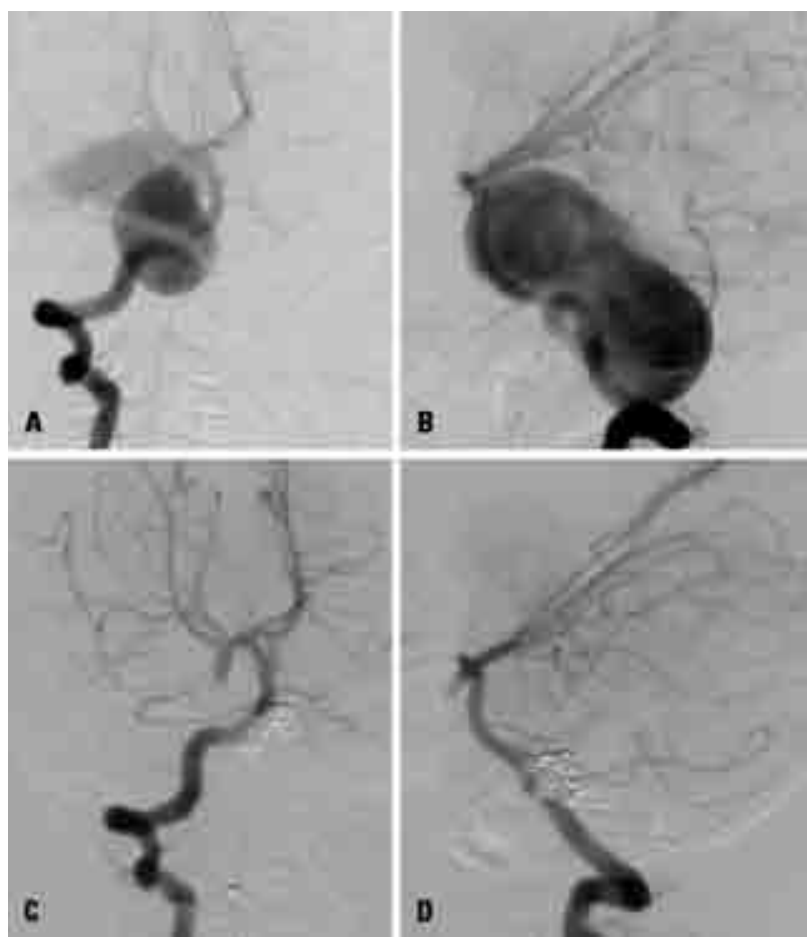

Fig 2. $[A]$ Angiography of right internal carotid artery anterior posterior views and in lateral views [B] confirmed AVF with single feeder originated from the vertebrobasilar junction and single draining in cerebellar vein toward torcule. [C] and [D] Postembolization internal carotid angiogram on anterior posterior and lateral views.

This pathology has different clinical presentations. Neonates can present with intractable cardiac failure and intracranial bruit. In infancy, it can present with hydrocephalus and seizures. Older children or young adults can present with intracranial hemorrhage ${ }^{1}$.

Owing to the absence of a nidus, closure of the shunt by either endovascular or surgical technique represents a satisfactory therapeutic procedure ${ }^{2}$. But the indications, the time, and the method of treatment chosen for management of AVFs depend on a variety of factors such as the age at presentation, presenting symptoms, the status of the brain, and the status of the other organs ${ }^{5}$.

In conclusion, emergent diagnosis and treatment of this pathology is crucial due to its associated with high morbidity and mortality. Endovascular techniques can provide safe and successful treatment for these infants.

\section{REFERENCES}

1. Meyers PM, Halbach VV, Barkovich AJ. Anomalies of cerebral vasculature: diagnostic and endovascular considerations. In: Barkovich AJ (Ed). Pediatric neuroimaging. $3^{\text {rd }}$ ed. Philadelphia: Lippincott Williams \& Wilkins, 2000;777-796.

2. Lasjaunias P, Manelfe C, Chiu M. Angiographic architectures of intracranial vascular malformations and fistulas: pretherapeutic aspects. Neurosurg Rev 1986;9:253-263.

3. Hoh BL, Putman CM, Budzik RF, et al. Surgical and endovascular flow 
disconnection of intracranial pial single-channel arteriovenous fistulae. Neurosurgery 2001;49:1351-1363.

4. Nelson K, Nimi Y, Lasjaunias P, et al. Endovascular embolization of congenital intracranial pial arteriovenous fistulas. Neuroimaging Clin N Am 1992;2:309-317.

5. Lasjaunias P, Ter Brugge KG, Berenstein A. Cerebral arteriovenous fistulas. In: Heilmann U (Ed). Surgical Neuroangiography 3. $2^{\text {rd }}$ ed. New York: Springer Verlag, 2006:227-270.

\section{FISTULA ARTERIOVENOSA PIAL NA FOSSA POSTERIOR}

'MD, Residente de Radiologia pelo Centro Diagnóstico por Imagem de Vitória (CDI), Vitória ES, Brazil; ${ }^{2} \mathrm{MD}$, PhD Neurocirurgião e Neurorradiologista
Intervencionista - Hospital Metropolitano e Vitória Apart Hospital, Serra ES, Brazil. Hospital Central de Vitória e Centro Integrado de Atenção a Saúde, Vitória ES, Brazil; ${ }^{3} \mathrm{MD}$, Residente de Radiologia, CDI; ${ }^{4} \mathrm{MD}$, Neurocirurgião e Neurorradiologista Intervencionista, Hospital Metropolitano e Vitória Apart Hospital, Serra ES, Brazil. Hospital Central de Vitória e Centro Integrado de Atenção a Saúde, Vitória ES, Brazil; ${ }^{\mathrm{M}}$ MD, Neurocirurgião, Hospital Metropolitano e Vitoria Apart Hospital, Serra ES, Brazil. Hospital Central de Vitória e Centro Integrado de Atenção a Saúde, Vitória ES, Brazil.

Correspondence: Leandro de Assis Barbosa - Rua Nicolau Von Schilgem 100/1103 - 29065-130 Vitória ES - Brasil. E-mail: leandro.assisbarbosa@gmail.com Received 1 March 2011, received in final form 7 April 2011. Accepted 14 April 2011

\title{
Extradural cavernous hemangioma of thoracic spine
}

\author{
Apio Antunes ${ }^{1}$, Mateus Felipe Lasta Beck², Atahualpa Caue Paim Strapasson², \\ André Cerutti Franciscatto ${ }^{2}$, Mateus Franzoi²
}

Cavernous hemangioma of the central nervous system is a vascular malformation which is a developmental hamartoma, also known as cavernoma or cavernous malformation or venous angioma ${ }^{1}$.

Cavernomas may affect any segment of the neuraxis. Most of these malformations are intracranial: supratentorial compartment is a site usually affected ${ }^{2,3}$. Pure spinal epidural cavernomas represent approximately $12 \%$ of spinal cavernous anomalies ${ }^{4}$ and the thoracic segment is the most frequently affected ${ }^{5}$. There are approximately 80 cases of epidural cavernous hemangioma published in the literature $e^{4,5}$.

We report on a case of thoracic extradural cavernous hemangioma, with emphasis on the clinical aspects.

\section{CASE}

A 63-years-old female caucasian patient with a previous history of cryptogenic epilepsy was referred to our emergency department with complaints of a one year history of gait ataxia, numbness and dysesthesia in both lower limbs. In the last 2 months, she also noticed reduced strength in the lower limbs.

Neurological examination showed reduced strength in the lower limbs, grade 4/5 in the right lower limb and grade $3 / 5$ in the left one. There was reduced sensation for all sensory modalities below the T10-11 dermatomes. There was also lower limb hyperreflexia and hypertonia, with bilateral extensor plantar response.

An MRI showed an epidural space-occupying lesion involving the T9-T10 spinal canal levels and extending to

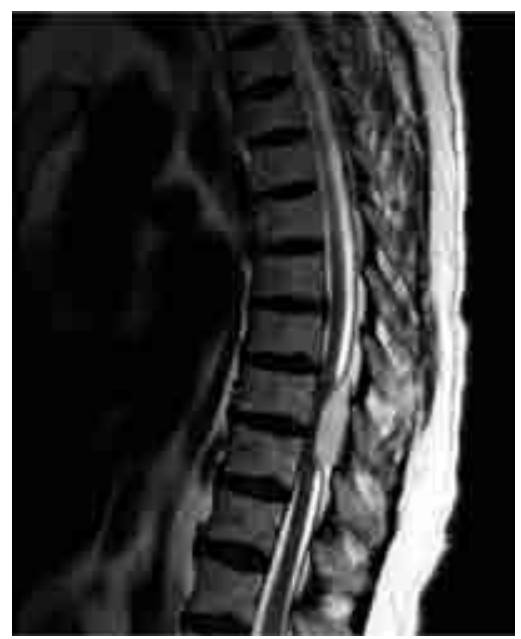

Figure. Preoperative MRI. Sagital T2-weighted image showing isodense lesion in the posterior extradural space at T9-T10 with ventral dislocation of the spinal cord.

the T9 left foramen, with an intense and homogeneous contrast enhancement (Figure).

The patient was submitted to a T9-T10 laminectomy, including a T9 left foraminectomy. A posterior soft and reddish epidural mass with a good cleavage plan was completely removed. The patient evolved with partial improvement of sensibility in both lower limbs and strength.

Histological examination revealed thin-walled blood vessels lined with a single layer of endothelial cells, surrounded by connective tissue. The microscopic appearance was compatible with cavernous hemangioma. 